\title{
Measuring Cost By Using Throughput Accounting to Rationalize Administrative Decisions
}

\author{
Submitted 02/03/20, $1^{\text {st }}$ revision $13 / 04 / 20,2^{\text {nd }}$ revision 20/05/20, accepted $30 / 07 / 20$
}

\section{Sabah Hasan Mijbil ${ }^{1}$, Ahmed Mohammad Hamzah ${ }^{2}$ Khudair Majeed Allawi ${ }^{3}$}

\begin{abstract}
:
Purpose: The study aims at analyzing the performance of selected companies by using throughput accounting. It is an attempt to measure cost and find out how applying throughput accounting rationalizes adiminstrative decisions.

Design/Methodology/Approach: The methodology used in this study is based on Throughput Accounting (TA) as a principle-based and simplified management accounting approaches. The General Company for Electrical Industries in Iraq was chosen to apply the practical aspect of the research due to the multiplicity of the products provided by the company.

Findings: Following modern production methods leads to committing the economic units to the need to improve methods of calculating costs in order to comply with the new production environment, as traditional cost systems have fallen short of providing the necessary information and appropriate standards, as well as the degree of accuracy that must be provided for the purpose of carrying out the management of the economic unit with its various activities and managing its resources effectively.

Practical Implications: The importance of this research comes from the role played by throughput accounting in addressing the negative effects resulting from mismanagement of all resources in the restricted activities.

Originality/Value: The research concluded that the use of throughput accounting in cost measurement leads to improving operational performance and assisting the administration in making decisions that maximize the value of the economic unit.
\end{abstract}

Keywords: Throughput accounting, management, rationalize, operational performance.

JEL codes: $M 21$.

Paper type: Research article.

\footnotetext{
${ }^{l}$ Ministry of Higher Education and Scientific Research, Department of Missions and Cultural Relation, Iraq.

${ }^{2}$ Summer University, College of Administration and Economics, Iraq

${ }^{3}$ Al-Furat Al-Awsat Technical University- Technical Institute, Diwaniya, Iraq khud.dw@atu.edu.iq
} 


\section{Introduction}

The modern manufacturing environment, in the light of the globalization of markets, imposed changing conditions at an accelerated pace with which it requires taking measures and steps to appropriate these changes in order to remain in the competition market. Maintaining existing customers and seeking to attract others requires quality of products and their formation and managing the available resources in a manner that ensures the flow of those resources in commercial activities without obstacles that lead to the failure of the economic unit to achieve its set goals. The aim is alo to commit to achieving the goals and increase profitability. Production companies seek ways and modern concepts to maximize the profitability of the economic units and manage its economic resources appropriately, and that is what the methods and means provide in terms of information that enables them to perform their functions and make decisions at a level that precipitates them more closely and faster in responding to these conditions.

Perhaps the concept of throughout accountability with its recent applications has contributed significantly through providing an information system in assisting economic units when confronting difficult conditions and problems. This concept has presented a modern perception about the cost structure by focusing directly on the cost of materials only as variable costs while all other costs are fixed, and this is what made them appropriate to the modern manufacturing environment and that is due to the low contribution of the human element to the dependence of this environment on automated work. In addition, throughout accounting in terms of information is useful for assisting the administration in planning profitability by selecting it for the optimal mix that achieves its highest profitability.

\section{Theoretical Background}

\subsection{The Concept of Throughout Accounting and Its Objectives}

Throughout accounting is one of the administrative accounting tools that are based on the main principles of the theory of restrictions, and focuses mainly on interest in managing restrictions imposed on the operational activities of the economic unit. Its work is complementary to the management system as it works to provide all the information that managers need in order to manage and control the restrictions of economic unit (Elsukova, 2015).

In the United Kingdom, between 1988-1989, Galloway and Waldron established throughout accounting from the theory of restrictions, which is similar in concept to the theory of restrictions, but is based on accounting principles while the theory of restrictions is not, and stressed the difference between the two systems. Throughout accounting is an extreme version in calculating the variable cost, as it considers direct material as a single variable in the cost of the product and all other costs, including fixed direct wages, and it works through a series of ratios that differ from 
all administrative accounting systems, as it focuses first, on completion, second reducing inventory and third controlling fixed costs (Wilks and Burke, 2008).

Throughout accounting assumes that each process has at least one restriction, whether it is equipment, workers, or procedures. It also imposes a traditional accounting philosophy which says that maximizing profitability is done through the maximum use of machinery and labour, showing that improving profitability is done by improving the flow during the whole process (Maynard, 2011). The main concept of throughout accounting stands for using profitability analysis at the level of the economic unit, instead of analysing profit margin at the product level, as opposed to accounting for traditional costs where we note that costs are collected from all sections of the production process and allocated in different ways to specific products and after subtracting this cost from the selling price of these products, in order to reach the gross profit margin which is used to determine whether the product is profitable enough or not for the purpose of its production (Bragg, 2017).

Bhimani et al. (2008) believe that throughout accounting is an administrative tool that works in part based on the theory of restrictions and focuses mainly on the rate that management can achieve in maximizing profits. The main point in this tool is focusing on the choke point (Bhimani et al., 2008, 716). Some define it as the revenue that the system generates by producing the products sold, while the traditional definition of productivity focuses on production per unit of time, whereas throughout accounting focuses on the product sold rather than just on the production, because products that are not sold do not generate revenue (Utku et al., 2011, 318).

\subsection{Using the Throughout Accounting Portal as a Tool to Rationalize Administrative Decisions}

The decision is a means to achieve the goals of the economic unit, because it mainly works to enable the economic unit to continue its operations efficiently and effectively, in addition to the fact that the decision focuses mainly on the future for the various periods (short, medium and long-term) and because of the potential of the future (Abd and Al-Razzaq, 2018). Decisions should be thought of as means, not ends. They are the regulatory mechanisms through which an attempt is made to achieve the desired state, and they are in fact an organizational response to the problem, where each decision is the result of a dynamic process affected by many forces (Gibson et al., 2012).

Different management accounting methods determine the product costs differently. Since cost information is used to make production mix decisions, manufacturing performance may be affected, and the emergence of control systems in manufacturing processes such as production on time and the theory of restrictions opens the door for new accounting techniques, including throughout accounting, which has contributed significantly through its focus on restrictions to achieve the maximum profitability of the economic unit (Wiks and Burke, 2008). Throughout 
accounting depends on sales because it is the only component by which the margin of achievement is completed, which necessitates not stopping at the volume of production as well as being the first sale, a shift in focus on sales as a way to measure actual efficiency and effectiveness, and this concept also depends on the compatibility between the margin of achievement and what it consumed from the costs of restricted activity so that you can classify products for the purpose of rationalizing the decisions regarding the best mix of products (Abu Shanaf, 2017).

Supporters of throughout accounting see a number of deficiencies in the ability to account for traditional costs in evaluating appropriate information to rationalize administrative decisions related in particular to choosing the optimal mix of products, because of their emphasis on reducing costs and improperly loading them, as well as adopting the principle of equal importance of available resources, which helps on the adoption of inappropriate decisions. Accordingly, throughput accounting has adopted the principle of loading products at the cost of direct materials only, but as for the fixed costs that do not change from the mix of other production to the stability of the energy resources related to them in the near term, there is no justification behind such downloading, apart from the fact that it may cause harm to the process of decision (Alawi et al., 2019).

This research study is based on a main hypothesis which states that using the throughout accounting approach leads to improving operational performance and assisting the administration in taking decisions that maximize the value of the economic unit.

\section{Methodology and Data}

The methodology used in this study is based on Throughout Accounting (TA) as a principle-based and simplified management accounting approach. The General Company for Electrical Industries in Iraq was chosen to apply the practical aspect of the research due to the multiplicity of the products provided by the company and because of the high cost of salaries that might have led to wasting the positive results of throughout accounting data. Moreover, one of the companies operating in the same sector was relied on in order to give a clear and integrated picture of this performance.

The inductive approach was relied on in preparing the research by referring to books, letters, university dissertations and scientific research, as well as the descriptive and analytical approaches. The data collected is analyzed depending on likert five-points scale where "strongly disagree" yields one point, number two "disagree" yields two points, choice number 3 "undecided" receives three points, number 4 "agree" gets four points and finally number five "strongly agree" yields five points. Fifty two respondents from eight different universities in Jordan replied to the questionnaire, and the data received is analyzed below. 


\section{Empirical Results}

The purpose of applying throughput accounting initially requires applying the main assumptions for this concept in order to first identify the cost structure for each product in light of throughout accounting, so as to complete each product in the stages that it goes through. The General Company for Electrical Industries in Baghdad produces air coolers of two types (large size and medium size), and according to throughout accounting, the cost structure is one of the direct materials that is the only variable component and is borne by the cost of the product. As for the other indirect costs, the costs of a period are considered as in Table.

Table 1. The cost of materials included in the manufacture of air coolers (per unit)

\begin{tabular}{|c|c|c|c|c|}
\hline No. & Name of the material & $\begin{array}{l}\text { Medium-sized air } \\
\text { cooler }\end{array}$ & $\begin{array}{l}\text { Large- } \\
\text { sized } \\
\text { air } \\
\text { cooler }\end{array}$ & $\begin{array}{c}\text { Relationship } \\
\text { to the } \\
\text { product } \\
\text { unit }\end{array}$ \\
\hline 1 & Galvanized iron 1.5 for water basin & 25430 & 32600 & direct \\
\hline 2 & Aluminum 1.2 for air fan & 9800 & 9800 & direct \\
\hline 3 & $\begin{array}{l}\text { Galvanized iron } 0.7 \text { for the outer } \\
\text { cover }\end{array}$ & 8400 & 8700 & direct \\
\hline & Total cost of direct materials & 43630 & 51100 & \\
\hline 4 & Electric motor & 14000 & 15000 & indirect \\
\hline 5 & Plastic tubes & 1000 & 1000 & indirect \\
\hline 6 & Tonic nail & 900 & 1100 & indirect \\
\hline 7 & Water pump & 2830 & 2830 & indirect \\
\hline 8 & Shaft & 500 & 500 & indirect \\
\hline 9 & Triple cable & 2600 & 2600 & indirect \\
\hline 10 & Electrodes & 750 & 750 & indirect \\
\hline 11 & Screws & 350 & 350 & indirect \\
\hline 12 & Dye & 4800 & 8000 & indirect \\
\hline \multicolumn{2}{|c|}{ Total cost of indirect materials } & 15730 & 20130 & \\
\hline & Total all-over cost & 72360 & 84230 & \\
\hline
\end{tabular}

Source: Created by the authors using the results of the study.

All costs of indirect materials, direct and indirect wages, and indirect industrial costs are fixed costs borne by the period in which they are achieved and their total amount is 35860 , which is calculated on a weekly basis by dividing the monthly expenses by four weeks due to the selection of the demand mix for the products on a weekly basis, as shown in Table 2.

In order to determine the restrictions, the process of determining the obstacles faced by the production process depends on the time each product spends in the production stages until it reaches the stage in which it becomes fully manufactured, and that can be determined by the next step of the application of production accounting. 
Table 2. Operating expenses

\begin{tabular}{|l|l|l|}
\hline No. & Account name & The amounts \\
\hline 1 & Salaries and wages & 10551250 \\
\hline 2 & Commodity supplies & 1591700 \\
\hline 3 & Service supplies & 962500 \\
\hline 4 & Extinction & 218750 \\
\hline & Total & 13324200 \\
\hline
\end{tabular}

Source: Created by the authors using the results of the study.

Thus, testing the results of the research is based on the weekly demand, so the available time is amounts to 2310 minutes per week measured as follows: $\{22$ working days $* 7$ hours (after excluding the lost time for workers' entry and exit times as well as a break of 1 hour) $* 60$ minutes / 4 weeks $\}$, where the two products go through a group of production stages that start cutting and then turning, general welding, dyeing, after which comes the important stage, which is full welding, and finally there is the assembly stage. Table 3 shows the amount of time calculated in minutes and the weekly application amount in each of the above stages, through which it becomes clear that the full welding stage is the point of suffocation and the existing handicap where extra time is required to complete so that orders can be produced in 240 minutes (2350-2550).

Table 3. The required quantities and the time needed to complete them in each section

\begin{tabular}{|c|c|c|r|r|l|l|l|}
\hline $\begin{array}{c}\text { Required Quantity / } \\
\text { Sections }\end{array}$ & Cutting & Turning & $\begin{array}{l}\text { General } \\
\text { welding }\end{array}$ & Dyeing & $\begin{array}{l}\text { Full } \\
\text { welding }\end{array}$ & Assembling & $\begin{array}{l}\text { Total } \\
\text { time }\end{array}$ \\
\hline $\begin{array}{c}50 \text { units, medium- } \\
\text { sized }\end{array}$ & 200 & 100 & 50 & 15 & 1150 & 770 & 2285 \\
\hline 40 units, large- sized & 200 & 120 & 60 & 20 & 1400 & 800 & 2600 \\
\hline Total & 400 & 220 & 110 & 35 & 2550 & 1570 & 4885 \\
\hline
\end{tabular}

Source: Created by the authors using the results of the study.

The completion margin amount is calculated on the basis of the weekly demand for air coolers, based on the cost of direct materials for the products shown in Table 1 as well as the amount of the request referred to Table 3, knowing that the selling price of the medium-sized air cooler is 90,000 dinars while the large-sized air cooler costs 140,000 dinars (Table 4).

Table 4. The amount of delivery margin for each product

\begin{tabular}{|c|c|c|}
\hline Products & Medium-sized air cooler & Large-sized air cooler \\
\hline Demand in units & 50 & 40 \\
\hline Unit sale price & 90000 & 140000 \\
\hline Unit variable cost & 43630 & 51100 \\
\hline $\begin{array}{c}\text { Delivery margin per } \\
\text { unit }\end{array}$ & 46370 & 88900 \\
\hline
\end{tabular}

Source: Created by the authors using the results of the study. 
Table 4 shows the increase in the margin of achievement in relation to the large size cooler, being more than $200 \%$ higher than the medium-sized cooler, which gives priority to this product in production. For the purpose of reaching the completion rate, the time required for one unit of the large size cooler is 65 minutes while the medium-sized cooler requires 45.7 minutes for the purpose of completion. Table 5 shows the completion rate for each product.

Table 5. Achievement rate for each product

\begin{tabular}{|c|l|c|c|}
\hline Product & $\begin{array}{l}\text { Delivery margin } \\
\text { per unit }\end{array}$ & $\begin{array}{l}\text { The time needed to } \\
\text { produce the unit }\end{array}$ & Achievement rate \\
\hline $\begin{array}{c}\text { Medium-sized air } \\
\text { cooler }\end{array}$ & 46370 & 45.7 & $\begin{array}{c}1015 \\
\text { dinars/minute }\end{array}$ \\
\hline $\begin{array}{c}\text { Large-sized air } \\
\text { cooler }\end{array}$ & 88900 & 65 & 1368 dinars/minute \\
\hline
\end{tabular}

Source: Created by the authors using the results of the study.

It turns out from the above that there are no restrictions in the first four of the stages that the producers go through to meet the production requirements, meaning that the available time for production amounting to 2310 minutes for each production stage is sufficient for the purpose of producing the production mixture for all producers, but the restriction is present in the fifth stage (the full welding stage), whereas in this stage the available time (2310 minutes) is not sufficient to complete the production mixture, as the time required to produce this mixture is 2550 minutes, so that there is a time shortage to complete the production mixture referred in Table 5. Note that the average completion rate for the large-sized cooler, 1368 dinars / minute, is larger than the average completion rate of the medium-sized cooler by $60 \%$, thus the priority in the production of any of the two air coolers in the restriction stage is for the large-sized cooler in its full amount because it achieves the largest productivity rate and the excess time in this restricted stage is used to produce the medium-size coolers that are in production. Table 6 shows the amount of the production mixture.

Table 6. Determining the production set in the restricted resource

\begin{tabular}{|l|c|l|l|l|}
\hline \multicolumn{1}{|c|}{ Products } & \multicolumn{1}{|c|}{$\begin{array}{c}\text { Product } \\
\text { demand } \\
\text { (units) }\end{array}$} & $\begin{array}{c}\text { Required time in } \\
\text { restricted phase } \\
\text { (minute) }\end{array}$ & $\begin{array}{l}\text { Available energy } \\
\text { (minute) }\end{array}$ & $\begin{array}{l}\text { Sales mixture } \\
\text { (units) }\end{array}$ \\
\hline $\begin{array}{l}\text { Medium-sized } \\
\text { air cooler }\end{array}$ & 50 & 1150 & 910 & 40 \\
\hline $\begin{array}{l}\text { Large-sized air } \\
\text { cooler }\end{array}$ & 40 & 1400 & 1400 & 40 \\
\hline
\end{tabular}

Source: Created by the authors using the results of the study.

As long as the optimum mix of production was determined by organizing production in the restricted resource where priority was given to the large-size cooler to produce 40 units which required 1400 minutes, the result left from the time of 910 minutes (2310-1400 minutes) would be used to produce 40 medium-sized cooler units 
(910/23 minutes). After identifying the units for each product, it is thus possible to calculate the net profit and return on investment as shown below in Table 7.

Table 7. Calculation of net profit and return on investment

\begin{tabular}{|l|c|l|c|}
\hline \multicolumn{1}{|c|}{ Products } & Sales mix & Unit completion rate & Total \\
\hline Large-sized air cooler & 40 & 88900 & 3556000 \\
\hline Medium-sized air cooler & 40 & 46370 & 1854800 \\
\hline & & Completion margin & 5410800 \\
\hline & & Operating expenses & $(13324200)$ \\
\hline & & Net profit / loss & $(7913400)$ \\
\hline
\end{tabular}

Source: Created by the authors using the results of the study.

\subsection{Total Production Time of Each Cooler / Quantity Required}

In addition to the role of throughout accounting in rationalizing the administrative decision when choosing the appropriate marketing mix for the products in question, what is even more important is its role in managing the profits of the economic unit by diagnosing the defects that lead to achieving losses in the activity of that unit (Table 7).

Despite choosing the optimal marketing mix by applying throughout accounting, it is clear that the economic unit achieved losses with this mix amounting of 7913400, and the reason for this is not the selection chosen for the production mix, but rather the operating expenses incurred by the economic unit to calculate salaries and wages. In particular, $80 \%$ of the total amount that has been accounted for, in addition to the dependence of the company in question on the payment of salaries and wages on the salary scale according to Law 22 of 2008 amended and the large inflation in the number of employees that leads to an increase in those wages in the accounting period. The current status of the exchange salaries and wages does not give any attention to the effort exerted in granting those wages and for the purpose of showing the negative effect of this neglect, the available information on the company in question will be used in Table 3 .

\section{Conclusion}

This study is an attempt to empirically examine the performance of selected companies by using throughout accounting. It is an attempt to measure cost and find out how applying throughput accounting rationalizes adiminstrative decisions. It is concluded that following the modern production methods leads to committing the economic units to the need to improve methods of calculating costs in order to comply with the new production environment.

The traditional cost systems have fallen short of providing the necessary information and appropriate standards as well as the degree of accuracy that must be provided for the purpose of carrying out the management of the economic unit with its various 
activities and managing its resources effectively. Consequently, the treatment of the current cost systems for the costs of the products may result in inaccuracy when calculating the unit cost of these products. The accuracy and clarity that characterize throughout accounting help in making decisions that have a positive reflection on the profitability of the economic unit while raising the efficiency of its performance.

Following the concept of throughout accounting helps to support management activities in planning and controlling costs. By focusing on achievement when calculating production costs fairly and appropriately, the economic units must be urged to take advantage of the information provided by managerial accounting techniques in general and throughout accounting in particular, taking into consideration the role of this instrument in cost measuring and information providing that helps to raise the efficiency of the economic performance of the unit and improve profitability

\section{References:}

AbdAl-Razzaq, Asma Muhammad. 2018. Differential earnings analysis using the theory of constraints and their role in decision-making. An applied study in the General Company for Cotton Industries. Master Thesis, College of Administration and Economics, University of Baghdad.

AbuShanaf, Zaid Salem. 2017. Evaluating the effectiveness of throughout accounting as a tool for determining costs in the restricted resource environment. The Journal of Commerce for Scientific Research, Alexandria University, First Issue.

Al-Hamdani, Bahaa Hussein and Al-Subaihi, Amer Dahham Khalaf. 2016. Accounting for production and its role in achieving and supporting throughout accounting. Journal of Economic and Administrative Sciences, College of Administration and Economics, University of Baghdad, No. 92, Volume 22, pp. 535-555.

Allawi, K.M., Mijbil, S.H., Salloomi, R.K. 2019. The compatibility between lean accounting and cleaner production for achieving competitive advantage. Polish Journal of Management Studies, 20(2).

Barqo, Nimr Al-Sham Shaibo and Ahmed, MoatazMirghani Sayyid. 2014. Integration between the cost method on the basis of activity of throughout accounting to increase the efficiency of cost measurement: An applied analytical study. University of Bahri, Journal of Arts and Humanities, Sudan, No. 6.

Bragg, S, 2017, Throughout accounting. A guide to constraint management. John Wiley \& Sons, Inc.

Elsukova, T.V. 2015. Lean accounting and throughout accounting. An integrated Approach, Mediterranean Journal of Social Sciences, 6(3). MCSER Publishing, Rome-Italy.

Gibson, J.L., Ivancevich Jr, J.M., Donnelly, H.J., Konopaske, R. 2012. Organizations: Behavior, Structure, Processes, Fourteenth Edition. Published by McGraw-Hill.

Jackman, S. 2016. Innovations in management accounting research and practice: Whatever happened to throughout accounting. University of Canterbury Christchurch, New Zealand.

Noreen, E., Roman, L.W., Maher, W.M. 2008. Theory of constraints, 2nd ed. John Wiley \& Sons, Inc. 
Novak, P., Papadaki, S., Hrabec, D., Popesko, B. 2016. Comparison of managerial implications for utilization of variable costing and throughput accounting methods. Journal of Applied Engineering Science, 14(3), 389, 351-360.

Orouji, M. 2016. Theory of constraints: A state-of-art review. Accounting, 45-52.

Simst, Z., Gunay, N.S., Vayvy, O. 2014. Theory of Constraints:

A Literature Review. Published by Elsevier Ltd, Procedia - Social and Behavioral Sciences, 150, 930-936.

Warren, C., Reeve, J., Duchac, J. 2009. Managerial Accounting, 10th. Ed. Thomson SouthWestern, a part of the Thomson Corporation.

Wilks, C. Burke, L. 2008. Management accounting-decision management. Elsevier's Science \& Technology Rights Department in Oxford, UK. 